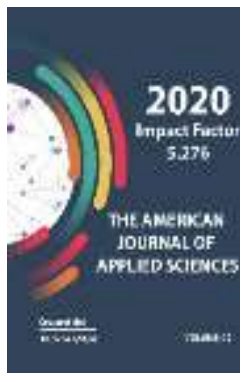

Journal Website: http://usajournalshub.c om/index,php/tajas

Copyright: Original content from this work may be used under the terms of the creative commons attributes 4.0 licence.

\section{Activity Concentrations Of Environmental Samples Collected In Samarkand Region Of Uzbekistan}

\section{G. Akhmedova}

Samarkand State University, Samarkand, Uzbekistan

R. Eshburiev

Samarkand State University, Samarkand, Uzbekistan

\section{U. Tukhtaev}

Samarkand State University, Samarkand, Uzbekistan

Sh. Khasanov

Institute Of Modern Physics, Chinese Academy Of Sciences, Lanzhou, China, University Of Chinese Academy Of Sciences, Beijing, China

\author{
A. Kahhorova \\ Samarkand State University, Samarkand, Uzbekistan \\ Sh. Sayfiev \\ Samarkand State University, Samarkand, Uzbekistan \\ E. Umarov \\ Samarkand State University, Samarkand, Uzbekistan
}

\title{
ABSTRACT
}

The results of the investigations of the activity concentration of natural radionuclides in certain building materials and foodstuff samples obtained from the Nurabad district of the Samarkand region of Uzbekistan are presented. The gamma radiation spectra of the samples were measured in Marinelli beaker geometry on $\gamma$ - spectrometer with a $\mathrm{Ge}(\mathrm{Li})$ detector and energy resolution $6 \%$ on the $1332 \mathrm{keV}$ line of ${ }^{60} \mathrm{Co}$. A personal computer and standard computer programs were used to accumulate and process the spectra. The characteristic density of the samples ranged from 140 to $1810 \mathrm{~g} / \mathrm{l}$. The activity concentration of ${ }^{40} \mathrm{~K}$ was observed to be comparatively higher than that of both ${ }^{226} \mathrm{Ra}$ and ${ }^{232} \mathrm{Th}$ in all the studied samples. The results reveal that the low activity of ${ }^{137} \mathrm{Cs}$ in the samples is attributed due to its half-life decay period.

\section{KEYWORDS}

Radionuclides, gamma radiation, spectrometer, building material, Uzbekistan. 


\section{INTRODUCTION}

The exposure of human beings to ionizing radiation from natural sources is a continuous and inevitable reality of life on Earth that can cause adverse biological consequences, such as DNA damage and cancer $[1,2,3]$. The causes of radioactivity in the atmosphere are known to be from naturally occurring radioactive materials and are classified as being of terrestrial or cosmic origin [4]. Radionuclides such as ${ }^{238} \mathrm{U},{ }^{226} \mathrm{Ra},{ }^{232} \mathrm{Th},{ }^{228} \mathrm{Ra},{ }^{228} \mathrm{Th}$, and ${ }^{40} \mathrm{~K}$ are the significant source of natural radiation exposure due to their natural occurrence in the Earth's crust or atmosphere. The average annual dose rate of radiation from naturallyoccurring radionuclides in a sample population is estimated to be $2.4 \mathrm{mSv}^{-1} \mathrm{y}^{-1}$ [5]. Besides, the use of radioactive isotopes for peaceful and military purposes has caused significant pollution to the environment with artificial radionuclides [6]. The study of radioactivity in the environment is useful in protecting human health and the environment from the adverse effects of ionizing radiation and is, therefore, of great importance [7]. Foodstuffs contain both natural and artificial radionuclides, which, after ingestion, can create a dose-effect [5]. An enormous contribution to dose exposure comes from the most crucial fission product, ${ }^{137} \mathrm{Cs}$. The literature of the current paper includes this type of studies [8, 9]. It is known that the whole life of a human being and its activity connected with living quarters. Therefore, in the construction of residential buildings, the study of the radiation characteristics of building materials is of considerable interest.

The current work presents gamma spectrometric studies of ${ }^{226} \mathrm{Ra},{ }^{232} \mathrm{Th},{ }^{40} \mathrm{~K},{ }^{137} \mathrm{Cs}$ in some building materials (burnt brick, cement, sand, limestone), and daily foodstuff (sugar, tea, table salt).

\section{MATERIALS AND METHODS}

A total of four samples of building materials and three samples of three kinds (domestic sugar, table salt, and tea imported from China) were selected for the measurements of activity concentrations from the Nurabad district of Samarkand region, Uzbekistan. All measurements were carried out in the Nuclear Physics Laboratory of Samarkand State University. The investigations were performed in Marinelli beaker geometry on $\gamma$ - spectrometer with a $\mathrm{Ge}(\mathrm{Li})$ detector $(\mathrm{V}=100$ $\left.\mathrm{cm}^{3}\right) \Delta \mathrm{E}_{\gamma}=6 \mathrm{keV}$ at $\mathrm{E}_{\gamma}=1332 \mathrm{keV}$ ). An IBM PC performed the registration and processing of the spectrometric data for 6 hours, and the data were automatically recorded every hour in the memory of the PC. For calibration of the registration efficiency of $\gamma$-radiation for the processing of the measured spectra, we used the volumetric standard sources $\mathrm{OMACH}^{232} \mathrm{Th}$, ${ }^{226} \mathrm{Ra},{ }^{40} \mathrm{~K}$ and ${ }^{137} \mathrm{Cs}$ with a density of inert fillings $\rho=140-1810 \mathrm{~g} / \mathrm{l}$ [10]. The error in the determination of the specific activity of radionuclide was $\delta(A)=8-16 \%$. When determining the specific activity of ${ }^{137} \mathrm{Cs}$, the error reaches up to $\delta(A)=25 \%$.

\section{RESULTS AND DISCUSSION}

The gamma spectra of the analyzed building material samples revealed the gamma radiation line of the naturally radioactive nuclide ${ }^{40} \mathrm{~K}$ with the intensity of $1460 \mathrm{keV}$ and gamma radiation, radionuclides belonging to the natural radioactive families of ${ }^{238} \mathrm{U},{ }^{232} \mathrm{Th}$. Gamma lines of radionuclides were detected in the ${ }^{238} \mathrm{U}$ family decay chain: ${ }^{214} \mathrm{~Pb}(295 ; 351 \mathrm{keV})$, ${ }^{226} \mathrm{Ra}(609 ; 1764 \mathrm{keV})$ and in the ${ }^{232} \mathrm{Th}$ decay chain - ${ }^{212} \mathrm{~Pb}(238 \mathrm{keV}),{ }^{228} \mathrm{Ac}(911 ; 968 \mathrm{keV}),{ }^{208} \mathrm{TI}$ $(583 ; 2614 \mathrm{keV})$. There is a weak gamma line of technogenic radionuclide ${ }^{137} \mathrm{Cs}$ with an energy of $661 \mathrm{keV}$ in the spectra of bricks, sand, and 
lime. Moreover, in general, the intensity of the background spectrum is much greater than that of the radionuclides being studied. As can be seen, the radioactivity of the studied building materials is mainly due to gamma radiation generated by the decay of natural radionuclides ${ }^{40} \mathrm{~K},{ }^{232} \mathrm{Th},{ }^{226} \mathrm{Ra}$, and partially ${ }^{137} \mathrm{Cs}$ (Fig. 1.).

The results of foodstuffs gamma-spectra reveal (Fig. 2):

- In the spectrum of gamma radiation of sugar, the intensity of gamma lines identified by radionuclides is determined at the background level;

- A gamma-line of natural radionuclide ${ }^{40} \mathrm{~K}$ with an energy of $1460 \mathrm{keV}$ and a weak gamma-line of uranium-series radionuclide - ${ }^{226} \mathrm{Ra}(1764 \mathrm{keV})$ identified in the gammaray tea spectrum, which exceeds the intensity of those gamma-lines in the background spectrum.

- In the gamma spectrum of table salt, detected lines of gamma radiation of the thorium radionuclide ${ }^{208} \mathrm{Tl}$ (583 keV; 2614 $\mathrm{keV}$ ) are determined at the background level; the intensity of the gamma line ${ }^{226} \mathrm{Ra}$ ( $1764 \mathrm{keV}$ ) exceeds the intensity of this line in the background spectrum.

Thus, the sugar radioactivity was determined at the background level, the table salt radioactivity is due to ${ }^{226} \mathrm{Ra}$, and the green tea radioactivity is primarily due to ${ }^{40} \mathrm{~K}$ and partially ${ }^{226} \mathrm{Ra}$.

The specific activity of radionuclides detected in the studied samples' spectra is determined by the intensity of the corresponding analytical lines.

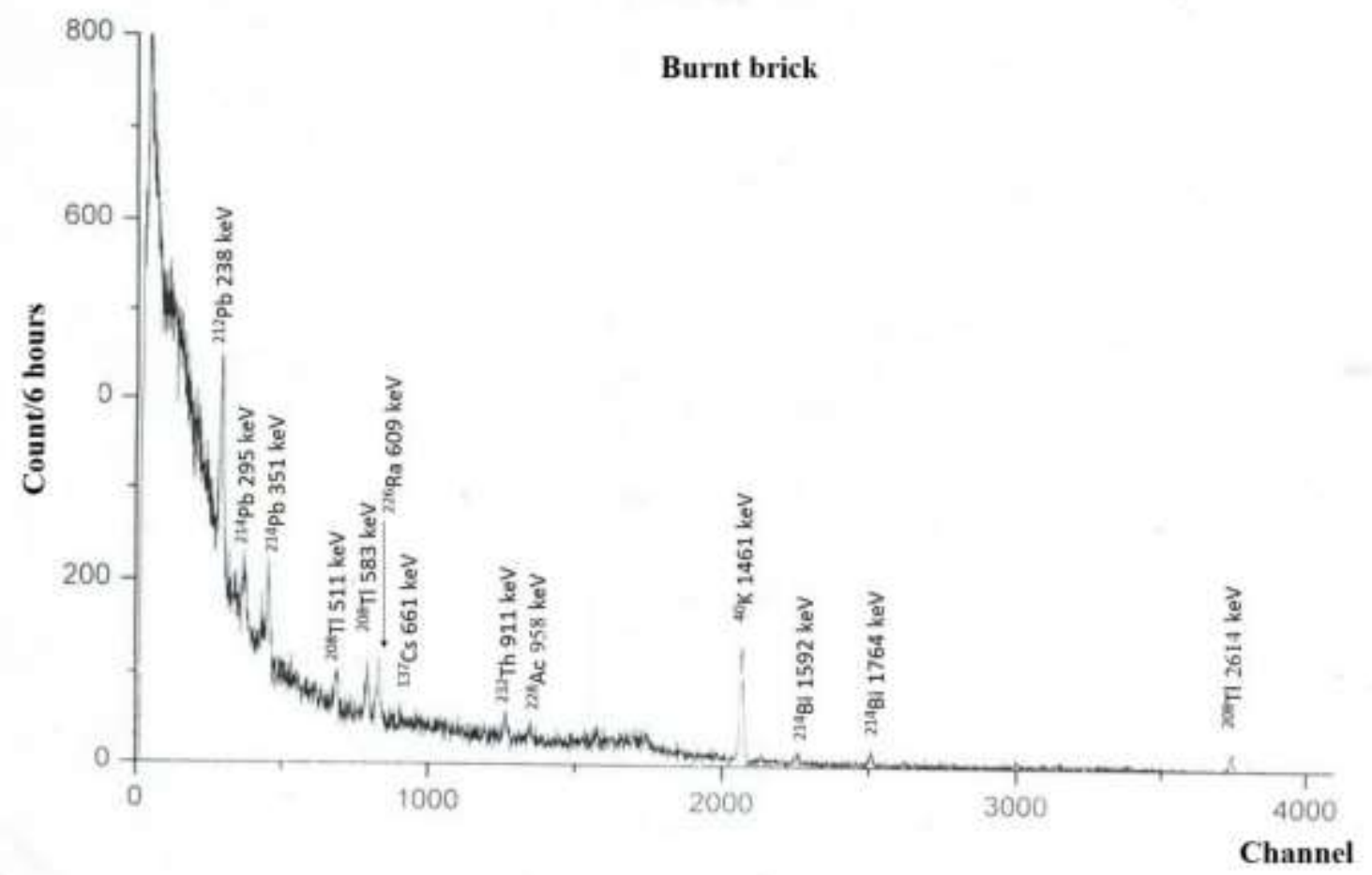

Figure 1. Gamma spectrum of burnt brick. 
The results of determining the specific activity of ${ }^{226} \mathrm{Ra},{ }^{232} \mathrm{Th},{ }^{40} \mathrm{~K}$, and ${ }^{137} \mathrm{Cs}$ in the studied samples of some building materials and foodstuff are shown in the table 1.

Table 1. Specific gamma activity of radionuclides detected in the gamma spectra of the studied samples, Bq/kg

\begin{tabular}{ccccc}
\hline Samples & ${ }^{226} \mathbf{R a}$ & ${ }^{232} \mathrm{Th}$ & ${ }^{40} \mathrm{~K}$ & ${ }^{137} \mathbf{C s}$ \\
Burnt brick & 30 & 28 & 212 & 1.5 \\
Cement & 23 & 8 & 44 & - \\
Limestone & 12 & 4 & 26 & 0.83 \\
Sand & 13 & 16 & 568 & 1.7 \\
Sugar & - & - & - & - \\
Table salt & 7.3 & - & - & - \\
Tea (green) & 6.3 & - & 403.6 & - \\
Worldwide average & 32 & 45 & 412 & \\
\hline
\end{tabular}

Worldwide average activity levels can be accessed in UNSCEAR report [11].

As can be seen from the table, the gamma activity of ${ }^{226} \mathrm{Ra},{ }^{232} \mathrm{Th},{ }^{40} \mathrm{~K}$, and ${ }^{137} \mathrm{Cs}$ in the studied building materials has different values. In all the samples studied, ${ }^{40} \mathrm{~K}$ gamma activity is determined in the most considerable amount in sand and brick, $568 \mathrm{~Bq} / \mathrm{kg}$, and 212
$\mathrm{Bq} / \mathrm{kg}$, respectively. This can be interpreted by the fact that potassium is prevalent with $2.4 \%$ in the Earth's crust. The gamma activity of ${ }^{226} \mathrm{Ra}$ and ${ }^{232} \mathrm{Th}$ is different for different materials. Bricks, lime, and cement prepared under various technological conditions that can affect the radioactivity of these materials. The central mass of radioactive elements is contained in rocks. Soil and sand are created 
by rock destruction, which occurs during weathering, changes in temperature, and other natural reagents.
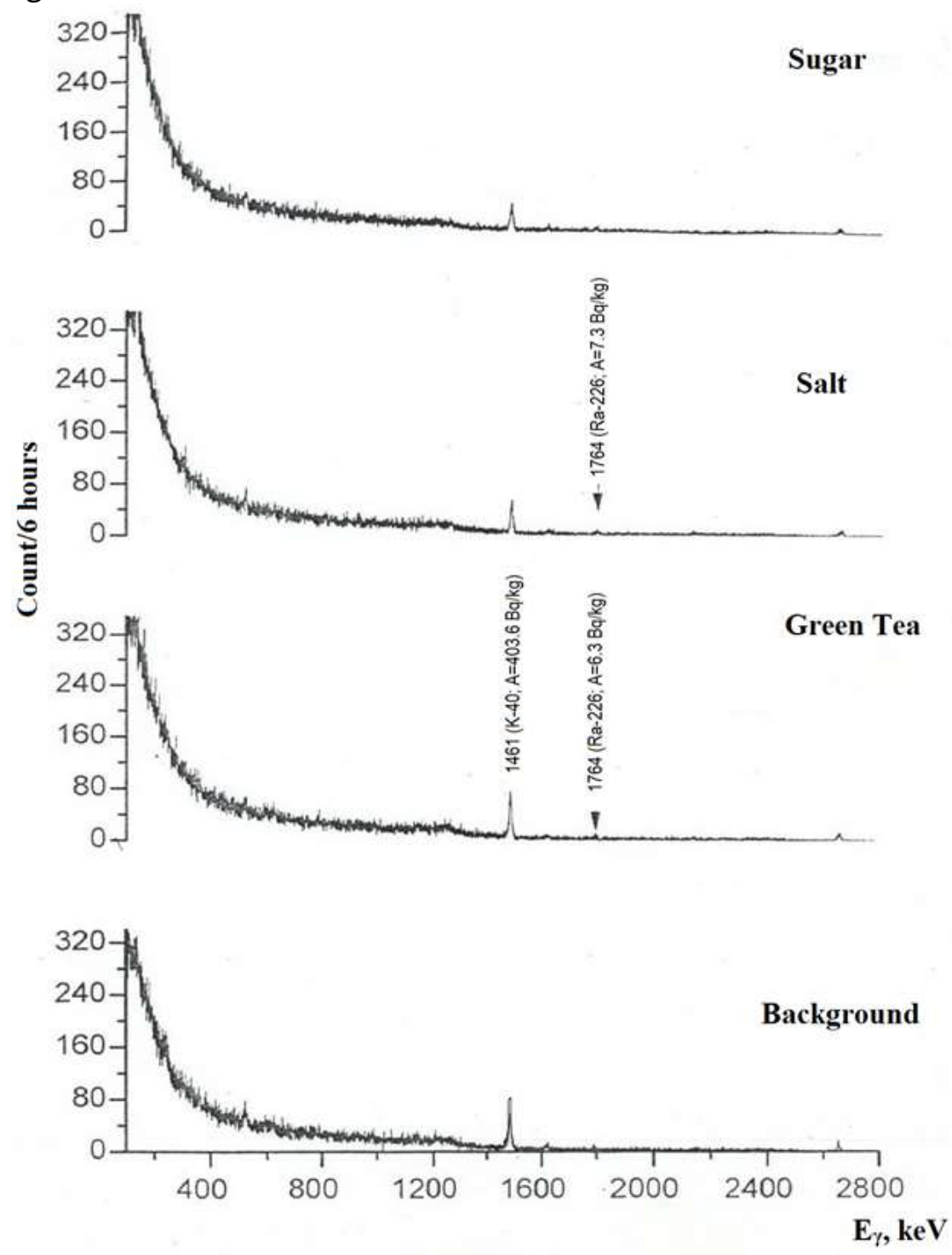

Figure 2. Gamma-spectra of some foodstuff

The primary source of radioactive elements contained in soil and sand are soil-forming rocks. Soil and water (clay) are used as raw materials for the production of burnt bricks [12]. Therefore, in a burnt brick, the natural radionuclides contained in the soil are determined.
Comparing the individual data values in table 1 with the worldwide average values, the obtained means are almost below the desired values. For building material sample, sand had the only exceeding activity value with $568 \mathrm{~Bq} / \mathrm{kg}$.

The determination of natural radionuclides in cement has also explained that different rocks 
are used as the starting material for cement production. In lime, the smallest amount of radionuclides is determined. As indicated in [13] relatively low content of radioactive elements characterizes limestones. This is likely why the concentration of radioactive elements in lime is determined in the smallest amount in our research.

In the gamma spectra of bricks, lime, and sand, a weak gamma line of the technogenic radionuclide ${ }^{137} \mathrm{Cs}$ with an energy of $661 \mathrm{keV}$ is identified. In contrast, in the gamma spectrum of cement, this line is not detected in the sensitivity limit of the gamma spectrometer. The difference in the specific activity of ${ }^{137} \mathrm{Cs}$ in brick and sand is insignificant, i.e. $(1.5-1.7)$ $\mathrm{Bq} / \mathrm{kg}$, and in lime $0.83 \mathrm{~Bq} / \mathrm{kg}$. The detection of ${ }^{137} \mathrm{Cs}$ can be understood by considering its halflife decay period $\mathrm{T}_{1 / 2}\left({ }^{137} \mathrm{Cs}\right)=30$ years .

Sugar, by its formation, belongs to the group of carbohydrates-disaccharides and has the structure formula $\mathrm{C}_{12} \mathrm{H}_{22} \mathrm{O}_{11}$. The most common disaccharides are sucrose (cane and beet sugar). Carbohydrates are an essential class of naturally occurring compounds that contain a carbon group. Carbohydrates include sugar, starch, cellulose, and some antibiotics. As seen from the gamma spectrum of sugar, the technology for producing sugar purifies it from various elements, including radioactive elements that determine in primary sources (beets, cane). Ordinary table salt, which is common in nature, is sodium chloride and has a NaCl-type structure. The spectrum shows one weak gamma line of the natural radionuclide ${ }^{226} \mathrm{Ra}(1764 \mathrm{keV})$, which exceeds this line's intensity in the background spectrum. Table salt in nature exists as a saline solution or substantial deposits in the earth's crust and surface. In any case, the source of salt deposits was the water of the ancient seas. It formed a deposit of table salt and salt lakes. Some seas dried up millions of years ago, and others still exist with abundant water. Table salt is obtained mainly by mining stone or self- seeding salt extracted from salt lakes, which naturally deposits itself.

Table salt of natural marine origin almost always has impurities of other minerals, so the visible detection in the spectrum of table salt ${ }^{226} \mathrm{Ra}$ is associated with an impurity of other minerals. Tea is obtained from the leaves of a shrubby plant. In the course of their development, plants carry out a complex cycle of synthesis of compounds necessary for existence both on land and in the aquatic environment. At the same time, along with organic substances, all known natural radionuclides accumulate in plants. Thus, in plants can be present radionuclides that contained in the soil, in water, and air. In the gamma spectrum of the tea we studied, gamma lines of natural radionuclides ${ }^{40} \mathrm{~K}$ and ${ }^{226} \mathrm{Ra}$ were detected, the intensity of which exceeds the background. In this case, no other natural radionuclides were detected in the sensitivity limit of the gamma spectrometer. In the spectra of gamma radiation of sugar, salt and tea line technogenic radionuclide ${ }^{137} \mathrm{Cs}$ was not detected.

\section{CONCLUSION}

In the present study, a gamma spectrometry based the $\mathrm{Ge}(\mathrm{Li})$ detector was employed for determination of the activity concentration of ${ }^{226} \mathrm{Ra},{ }^{232} \mathrm{Th},{ }^{40} \mathrm{~K}$, and ${ }^{137} \mathrm{Cs}$ in samples of some building materials and foodstuffs in Samarkand region in Nurabad, Uzbekistan. The observed activity concentrations means of radionuclides, apart from ${ }^{40} \mathrm{~K}$, were under the worldwide means by UNSCEAR as shown in table 1.

In summary, the results obtained can be useful in obtaining information on the degree of the radioactivity of samples used in this work for comparison to future monitoring studies.

\section{ACKNOWLEDGEMENT}


The authors would like to appreciate the Nuclear Physics Laboratory, Department of Physics, Samarkand State University for providing the facilities to carry out this research work.

\section{CONFLICT OF INTEREST}

On behalf of all authors, the corresponding author states that there is no conflict of interest.

\section{REFERENCES}

1. Little, M.P. (2003). Risks associated with ionizing radiation: Environmental pollution and health. British medical bulletin, 68(1), 259-275.

2. Ravanat, J.L., Breton, J., Douki, T., Gasparutto, D., Grand, A., Rachidi, W., \& Sauvaigo, S. (2014). Radiation-mediated formation of complex damage to DNA: a chemical aspect overview. The British journal of radiology, 87(1035), 20130715.

3. Schmid, E., \& Schrader, T. (2007). Different biological effectiveness of ionising and non-ionising radiations in mammalian cells. Advances in Radio Science, 5.

4. Kathren, Ronald L. "NORM sources and their origins." Applied radiation and isotopes 49.3 (1998): 149-168.

5. Unscear, S. (2000). Effects of lonizing Radiation. United Nations, New York, 453487.

6. Livingston, H.D., \& Povinec, P.P. (2000). Anthropogenic marine radioactivity. Ocean \& Coastal Management, 43(8-9), 689-712.

7. Ulanovsky, A., Pröhl, G., \& Gómez-Ros, J. M. (2008). Methods for calculating dose conversion coefficients for terrestrial and aquatic biota. Journal of Environmental Radioactivity, 99(9), 1440-1448.

8. Mamatkulov, O.B., Khasanov, Sh.Kh., \& Mavlonov, T.T. (2019). Determination the activity of the natural radioactive isotope $\mathrm{K}-40$ and the technogenic radionuclide Cs137 in the trunks and fruits of perennial trees//Journal of Technical and Natural Sciences, 2 (11), 29-33.
9. Azimov, A.T., Mamatkulov, O., Safarov, A.A., Khalikulov, Z.A., Bazarbaev, N.N., Inoyatov, A.K., ... \& Khudaiberdiev, A.T. (2016). Radionuclides in lichens, plants, and soil in the spurs of the Zarafshan Mountain Range. Atomic Energy, 120(4), p.285.

10. Certificate N110/905, 1995 Russian Research Institute of Metrology named after D. Mendeleyev, Saint-Petersburg, Russian Federation.

11. UNSCEAR (United Nations Scientific Committee on the Effects of Atomic Radiation), Sources and Effects of lonizing Radiation. UNSCEAR 2008 Report, Annex $B$, Exposures of the Public and Workers from Various Sources of Radiation, United Nations, New York, 2010.

12. Cabadas-Báez, Héctor Víctor, et al. "Soils as a source of raw materials for ancient ceramic production in the Maya region of Mexico: Micromorphological insight." Boletín de la Sociedad Geológica Mexicana 70.1 (2018): 21-48.

13. Saukov, A.A., The Earth's Radioactive Elements [in Russian]. Moscow, Gosatomizdat (1961). 